\title{
Postnatal treatment using curcumin supplements to amend the damage in VPA-induced rodent models of autism
}

\author{
Maha Al-Askar ${ }^{1}$, Ramesa Shafi Bhat ${ }^{1}$, Manar Selim², Laila Al-Ayadhi ${ }^{3,5,6}$ and Afaf El-Ansary 4,5,6*
}

\begin{abstract}
Background: Valproic acid (VPA) is used as a first-line antiepileptic agent and is undergoing clinical trials for use as a treatment for many disorders. Mothers undergoing VPA treatment during early pregnancy reportedly show increased rates of autism among their offspring. The benefits of curcumin supplementation were investigated using an animal model of VPA-induced autism.
\end{abstract}

Methods: The study was performed using a rodent model of autism by exposing rat fetuses to valproic acid (VPA) on the 12.5th day of gestation. At 7 days from their birth, the animals were supplemented with a specific dose of curcumin. Forty neonatal male Western Albino rats were divided into four groups. Rats in group I received only phosphate-buffered saline, rats in group II were the prenatal VPA exposure newborns, rats in group III underwent prenatal VPA exposure supplemented with postnatal curcumin, and rats in group IV were given only postnatal curcumin supplements.

Results: VPA rats exhibited delayed maturation and lower body and brain weights with numerous signs of brain toxicity, such as depletion of IFN- $\gamma$, serotonin, glutamine, reduced glutathione, glutathione S-transferase, lipid peroxidase with an increase in CYP450, IL-6, glutamate, and oxidized glutathione. A curcumin supplement moderately corrected these dysfunctions and was especially noticeable in improving delayed maturation and abnormal weight.

Conclusions: Curcumin plays a significant therapeutic role in attenuating brain damage that has been induced by prenatal VPA exposure in rats; however, its therapeutic role as a dietary supplement still must be certified for use in humans.

Keywords: Autism, Neurodevelopment valproic acid, Curcumin, Glutathione, Serotonin, Cytokines

\section{Background}

Experimental animal models of autism can help researchers understand the etiology of autism in humans and explore various supplements used to amend the impaired biomarkers related to the disease [1]. In reality, autism manifests as a set of behavioral changes, and the behavior of an animal model can never be the same as the behavior of an autistic child, but these behaviors can be scrutinized using precise experiments to measure the behavioral modifications. [2, 3] Currently, different approaches are used to induce human-like autistic features in rodent models by exposing animals to certain chemicals, such as valproic acid

\footnotetext{
* Correspondence: elansary@ksu.edu.sa; afafkelansary@gmail.com

${ }^{4}$ Central Laboratory, Female Center for Medical Studies and Scientific Section, Riyadh, Saudi Arabia

${ }^{5}$ Autism Research and Treatment Center, Riyadh, Saudi Arabia

Full list of author information is available at the end of the article
}

(VPA), since VPA significantly increases the rate of autism among the offspring of human mothers who are medicated with VPA during early pregnancy [4]. VPA exposure during the first trimester of conception is associated with risk of autism in the child, particularly if exposure occurs during the time of neural tube closure [5]. Thus, our rodent models showing autistic features were male Wistar neonatal rats originating from valproate-treated females [6]. These females received a single intraperitoneal injection of $600 \mathrm{mg} / \mathrm{kg}$ of sodium valproate on day 12.5 after conception.

For many years, VPA, a branched short-chain fatty acid, was used as a first-line antiepileptic agent, particularly in children suffering from epilepsy. [7] Presently, this drug is in clinical trials for use in the treatment of many disorders, however various consequences such as fatal hemorrhaging, pancreatitis, bone marrow suppression, hepatotoxicity, and 
hyperammonemic encephalopathy are associated with its use. VPA acts on $\gamma$ amino butyric acid (GABA) levels, changes the activity of many neurotransmitters, and blocks $\mathrm{Na}+$ channels, $\mathrm{Ca} 2+$ channels and voltage-gated channels in brain tissue [8]. Many studies have shown that valproate exposure in utero is associated with increased risk of neural tube defects, neurodevelopmental deficits and reduced vocal skills. [9-11].

Curcumin is known for its protective actions against various central nervous system disorders such as Alzheimer's disease, tardive dyskinesia, major depression, epilepsy, neurodegenerative disorders and neuropsychiatric disorders [12]. It can cross the blood brain barrier and is nontoxic at high doses [13]. Many studies have proved that curcumin targets multiple degenerative pathways including oxidative/ nitrosative stress, mitochondrial dysfunction, and protein aggregation [14]. Curcumin was effective in ameliorating propionic acid-induced autism in rats through the suppression of oxidative stress, mitochondrial dysfunction and neuroinflammation [14]. All reported biological activities of curcumin could potentially be of interest as autism therapies. Therefore, we studied the therapeutic effects of curcumin in VPA-induced animal models of autism.

\section{Methods \\ Chemicals}

Curcumin from Curcuma longa (Turmeric) (powder, $50 \mathrm{~g}$ in a glass bottle) and valproic acid sodium salt (powder, $25 \mathrm{~g}$ in a glass bottle) were obtained from Sigma. The catalog numbers are C1386 and P4543, respectively.

\section{Animals}

Female Wistar rats (180-200 g) that were acclimated in our laboratory under standard laboratory conditions with a controlled fertility cycle were obtained from the Center for Laboratory Animals and Experimental Surgery at King Khalid University Hospital, Riyadh. Rats were mated overnight, and the pregnant rats were divided into 2 sets. On day 12.5 after conception, set I was injected with a single intraperitoneal injection of normal saline, and set II was injected with a single

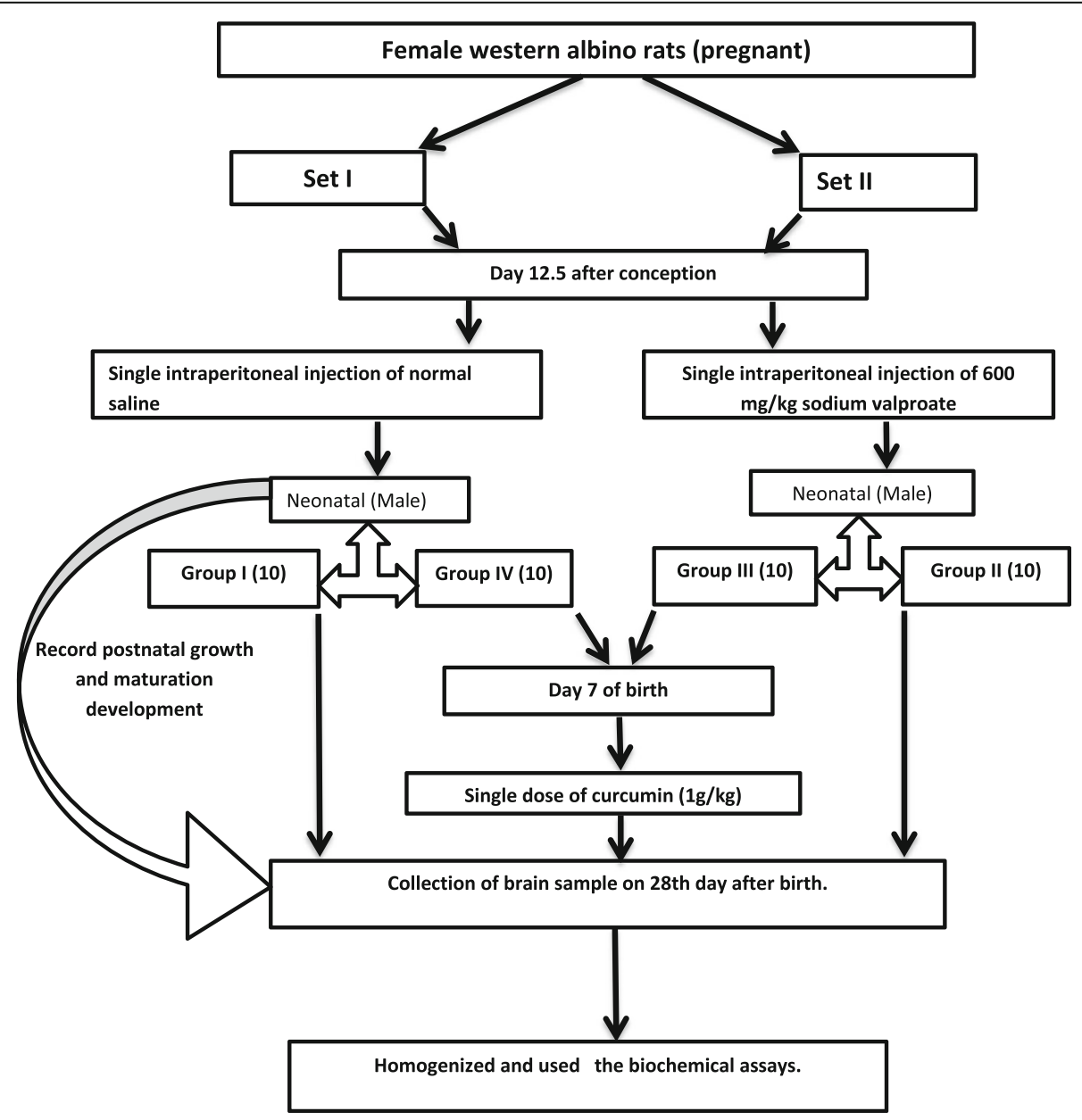

Fig. 1 Schematic presentation of the designed experiment 
intraperitoneal injection of $600 \mathrm{mg} / \mathrm{kg}$ of sodium valproate [15]. Twenty Male Wistar neonatal rats that were born from each set of females (treated with normal saline and VPA) were further divided into two groups of ten pups each. Finally, four groups (10 neonatal rats each) were organized as follows:

Group I (control): Male pups from set I was given an oral dose of $1 \mathrm{ml}$ of normal saline on day 7 after birth.

Group II (VPA rodent model): Male pups from set II (valproate treated mothers) were given an oral dose of $1 \mathrm{ml}$ of normal saline on day 7 after birth.

Group III (VPA-Curcumin): Male pups from set II (valproate treated mothers) received $1 \mathrm{ml}$ of curcumin (1 g/kg b.wt) [16] orally at 7 days after birth.

Group IV (Curcumin): Male pups from set I received $1 \mathrm{ml}$ of curcumin $(1 \mathrm{~g} / \mathrm{kg}$ b.wt) [16] orally at 7 days after birth. Figure 1 summarizes the experimental design and the different groups that were studied.

\section{Postnatal growth and maturation development}

Animals were weighed at $0,7,14,21$ and 27 days after delivery. See the uploaded diagram that illustrates the experimental design.

\section{Tissue preparation}

On the 28th day after birth, all groups were killed by decapitation. The brains were quickly collected, weighed, washed with normal saline and then homogenized in 10 times $w / v$ bi-distilled water and further used in the biochemical assays.

\section{Biochemical analyses}

Tissue samples were run concordant with the instructions of the kit protocol. The quantification of interleukin- 6 , interferon gamma, and reduced glutathione in the brain tissue were determined using a rat ELISA Kit obtained from "My Bio Source" that were based on a quantitative sandwich immunoassay technique, while for cytochrome P450, enzyme-linked immune sorbent assay, based on the biotin double antibody sandwich technology obtained from "My Bio Source", was used. The quantification of lipid peroxide, glutathione S-transferases, glutamine, and glutamate in the brain tissue was determined using the ELISA Kit based on a quantitative sandwich immunoassay technique obtained from "Cusabioin".

The quantification of serotonin in the brain tissue was carried out using a 5-HT ELISA Kit, which applies the competitive enzyme immunoassay technique utilizing a monoclonal

Table 1 Mean \pm S.D. together with the independent t-test for weight gain, brain weight and age of eye opening between neurointoxicated, protected and therapeutically treated rat pups compared to healthy control

\begin{tabular}{|c|c|c|c|c|c|c|c|c|}
\hline Parameter & Group & $\mathrm{N}$ & Min & Max & Mean \pm S.D. & Percent Change & $P$ value ${ }^{a}$ & $P$ value ${ }^{b}$ \\
\hline \multirow[t]{4}{*}{ Started weight (g) } & Control & 10 & 14.80 & 20.00 & $17.62 \pm 1.96$ & 100.00 & & \\
\hline & VPA & 10 & 14.90 & 18.80 & $17.47 \pm 1.38$ & 99.15 & 0.845 & 0.001 \\
\hline & VPA-CUR & 10 & 24.50 & 31.70 & $27.81 \pm 2.82^{c}$ & 157.83 & 0.001 & \\
\hline & CUR & 10 & 15.20 & 18.20 & $16.46 \pm 1.04$ & 93.42 & 0.121 & \\
\hline \multirow[t]{4}{*}{ Final weight (g) } & Control & 10 & 26.10 & 78.90 & $58.42 \pm 21.45$ & 100.00 & & 0.001 \\
\hline & VPA & 10 & 17.20 & 75.40 & $42.21 \pm 27.85$ & 72.25 & 0.163 & \\
\hline & VPA-CUR & 10 & 69.30 & 100.30 & $88.18 \pm 12.10^{c}$ & 150.94 & 0.002 & \\
\hline & CUR & 10 & 55.60 & 70.00 & $63.22 \pm 5.61$ & 108.22 & 0.509 & \\
\hline \multirow[t]{4}{*}{ Weight Gained } & Control & 10 & 11.30 & 58.90 & $40.80 \pm 19.56$ & 100.00 & & 0.001 \\
\hline & VPA & 10 & -0.30 & 60.30 & $24.74 \pm 28.56$ & 60.64 & 0.162 & \\
\hline & VPA-CUR & 10 & 44.80 & 72.90 & $60.37 \pm 9.80^{c}$ & 147.97 & 0.014 & \\
\hline & CUR & 10 & 40.40 & 51.80 & $46.76 \pm 4.80$ & 114.61 & 0.371 & \\
\hline \multirow[t]{4}{*}{ Brain weight (g) } & Control & 10 & 1.17 & 1.61 & $1.38 \pm 0.15$ & 100.00 & & \\
\hline & VPA & 10 & 1.12 & 1.63 & $1.31 \pm 0.17$ & 95.08 & 0.361 & 0.001 \\
\hline & VPA-CUR & 10 & 1.51 & 1.72 & $1.61 \pm 0.06^{c}$ & 116.54 & 0.001 & \\
\hline & CUR & 10 & 1.29 & 1.59 & $1.43 \pm 0.09$ & 103.58 & 0.377 & \\
\hline \multirow[t]{4}{*}{ Opening eyes (Days) } & Control & 10 & 15.00 & 16.00 & $15.30 \pm 0.48$ & 100.00 & & 0.001 \\
\hline & VPA & 10 & 10.00 & 17.00 & $14.50 \pm 3.21$ & 94.77 & 0.454 & \\
\hline & VPA-CUR & 10 & 14.00 & 16.00 & $15.20 \pm 1.03$ & 99.35 & 0.786 & \\
\hline & CUR & 10 & 11.00 & 13.00 & $12.00 .47^{c}$ & 78.43 & 0.001 & \\
\hline
\end{tabular}

\footnotetext{
${ }^{\mathrm{a}} P$ value between control group and other groups
}

${ }^{b} P$ value between all groups

${ }^{c}$ Indicates there is significant difference between the group and control at 0.05 level. 
anti-5-HT antibody and a 5HT-HRP conjugate, and for oxidized glutathione, a GSSG ELISA kit was used, which applies the competitive enzyme immunoassay technique utilizing a monoclonal anti-GSSG antibody and a GSSG-HRP conjugate, which were obtained from My Bio Source.

\section{Statistical analysis}

The Statistical Package for the Social Sciences (SPSS) computer program was used. The results were expressed as the mean \pm S.D., and all statistical comparisons were made using independent T-Tests, with values of $P \leq 0.05$ considered to be significant. Pearson's correlations were also performed, and the best fit line was drawn. Receiver operating characteristics (ROC) analysis was performed.
Area under the curve, cutoff values threshold, and degrees of specificity and sensitivity were calculated.

\section{Results}

The analysis of the body weight, brain weight and eye opening age in pups showed statistically significant $(P<0.001)$ differences in all tested groups compared with the control group, as shown in Table 1. VPA-exposed rats showed delayed maturation, as represented by lower body weight, a slight decrease in brain weight and late eye opening compared to the control group, whereas curcumin treatment was effective in promoting body and brain weight in VPAexposed pups (Table 1).

Table 2 Mean \pm S.D. together with the independent t-test for Interleukin-6, Interferon Gamma, cytochrome P450, Serotonin, Glutamine, Glutamate together with Glutamate/Glutamine Ratio in neuro-intoxicated, protected and therapeutically treated rat pups compared to healthy control

\begin{tabular}{|c|c|c|c|c|c|c|c|c|}
\hline Parameter & Group & $\mathrm{N}$ & Min & Max & Mean \pm S.D. & Percent Change & $P$ value $^{a}$ & $P$ value $^{\mathrm{b}}$ \\
\hline \multirow[t]{4}{*}{ IL-6 (pg\ml) } & Control & 10 & 4.50 & 22.29 & $12.59 \pm 6.07$ & 100.00 & & 0.019 \\
\hline & VPA & 10 & 3.61 & 24.96 & $15.47 \pm 7.56$ & 122.86 & 0.360 & \\
\hline & VPA-CUR & 10 & 4.50 & 11.61 & $7.96 \pm 2.22$ & 63.25 & 0.044 & \\
\hline & CUR & 10 & 3.61 & 16.95 & $9.87 \pm 3.86$ & 78.36 & 0.246 & \\
\hline \multirow[t]{4}{*}{ IFN-y (pg\ml) } & Control & 10 & 206.47 & 407.59 & $331.64 \pm 87.78$ & 100.00 & & 0.038 \\
\hline & VPA & 10 & 152.14 & 343.25 & $249.08 \pm 58.88$ & 75.10 & 0.024 & \\
\hline & VPA-CUR & 10 & 167.86 & 366.84 & $244.41 \pm 69.94^{c}$ & 73.70 & 0.024 & \\
\hline & CUR & 10 & 117.82 & 359.21 & $237.26 \pm 95.02^{c}$ & 71.54 & 0.033 & \\
\hline \multirow[t]{4}{*}{ CYP450 (ng\ml) } & Control & 10 & 33.02 & 40.16 & $36.46 \pm 1.79$ & 100.00 & & 0.085 \\
\hline & VPA & 10 & 33.85 & 42.01 & $39.11 \pm 2.64$ & 107.27 & 0.017 & \\
\hline & VPA-CUR & 10 & 34.62 & 43.83 & $37.50 \pm 2.82$ & 102.87 & 0.335 & \\
\hline & CUR & 10 & 34.14 & 43.83 & $38.96 \pm 2.92$ & 106.85 & 0.033 & \\
\hline \multirow[t]{4}{*}{$5 \mathrm{HT}$ (ng\ml) } & Control & 10 & 113.92 & 169.46 & $148.75 \pm 15.22$ & 100.00 & & 0.228 \\
\hline & VPA & 10 & 109.57 & 174.05 & $140.14 \pm 22.04$ & 94.22 & 0.323 & \\
\hline & VPA-CUR & 10 & 85.18 & 181.05 & $135.77 \pm 32.81$ & 91.28 & 0.278 & \\
\hline & CUR & 10 & 122.13 & 215.83 & $158.84 \pm 30.84$ & 106.78 & 0.366 & \\
\hline \multirow[t]{4}{*}{ Glutamine (pmol\ml) } & Control & 10 & 1640.31 & 2540.39 & $2186.87 \pm 302.70$ & 100.00 & & 0.001 \\
\hline & VPA & 10 & 1861.71 & 2549.07 & $2082.25 \pm 216.82$ & 95.22 & 0.386 & \\
\hline & VPA-CUR & 10 & 1456.53 & 2052.73 & $1763.15 \pm 165.27^{c}$ & 80.62 & 0.002 & \\
\hline & CUR & 10 & 1388.51 & 2324.78 & $1798.91 \pm 274.83^{c}$ & 82.26 & 0.008 & \\
\hline \multirow[t]{4}{*}{ Glutamate (nmol\ml) } & Control & 10 & 215.20 & 286.01 & $249.53 \pm 24.68$ & 100.00 & & 0.002 \\
\hline & VPA & 10 & 235.78 & 283.18 & $258.51 \pm 14.04$ & 103.60 & 0.334 & \\
\hline & VPA-CUR & 10 & 178.70 & 283.58 & $232.05 \pm 34.97$ & 92.99 & 0.213 & \\
\hline & CUR & 10 & 168.81 & 272.09 & $206.71 \pm 39.12^{c}$ & 82.84 & 0.009 & \\
\hline \multirow[t]{4}{*}{ Glutamate/Glutamine Ratio } & Control & 10 & 0.10 & 0.16 & $0.116 \pm 0.018$ & 100.00 & & 0.063 \\
\hline & VPA & 10 & 0.11 & 0.14 & $0.125 \pm 0.011$ & 108.04 & 0.169 & \\
\hline & VPA-CUR & 10 & 0.10 & 0.16 & $0.132 \pm 0.017$ & 113.83 & 0.051 & \\
\hline & CUR & 10 & 0.10 & 0.14 & $0.115 \pm 0.016$ & 99.65 & 0.963 & \\
\hline
\end{tabular}

${ }^{\mathrm{a}} P$ value between control group and other groups

${ }^{\mathrm{b}} P$ value between all groups

${ }^{c}$ Indicates there is significant difference between the group and control at 0.05 level 
Table 2 exhibits the significant depletion of IFN- $\gamma$ and non-significant depletion of $5 \mathrm{HT}$ and glutamine upon VPA exposure compared to the control group. CYP450 was significantly increased, while IL-6 and glutamate were non-significantly increased in VPA-exposed pups, and curcumin was effective in restoring nearly all the parameters, as shown in Table 2.

Table 3 shows lipid peroxide, oxidized glutathione, reduced glutathione, and glutathione $\mathrm{S}$-transferases levels in all of the treated groups, along with the GSH/GSSG ratios. Non-significant decreases in LPO and GSTs in the VPA group were observed in all treated groups compared to the control group. The same table demonstrates the significant decrease in GSH in VPA and VPA-CUR compared to the control group. GSSG showed a significant increase in all of the treated pups compared with the control group. Table 4 and Fig. 2 present the Pearson's correlations between the measured parameters.

Receiver operating characteristics curves are presented in Fig. 3. Area under the curve (AUC), cutoff values, sensitivity and specificity are listed in Tables 5,6 and 7

\section{Discussion}

Prenatal VPA exposure resulted in delayed maturation in newborns, as evidenced by lower body weight, a slight decrease in brain weight and late eye opening, indicating some altered neurodevelopmental effects. Our results validate many previous studies that suggest there is a maturational delay in the early stage of life of VPA-exposed rats [17]. Significant effects of postnatal curcumin treatments were found, that ameliorated all of the observed development delays in the current study. These results indicate the therapeutic potential of curcumin as a neuroprotective agent in the treatment of delayed maturation. Our results are consistent with many recent studies on discovering redevelopment and accelerating motor functional recovery of curcumin treatment in mice [18].

Elevated levels of IL-6 in the CNS have been reported in a number of neurological diseases that are associated with brain injury or inflammation [19]. In the current study, VPA exposure amplified the level of IL- 6 in the brain tissue, which may be due to neuroinflammation and altering the immune response during brain development. However, curcumin treatment was able to decrease IL-6 levels, as curcumin can suppress the pro-inflammatory gene expression by

Table 3 Mean \pm S.D. together with the independent t-test for Lipid Peroxide, Oxidized Glutathione, Reduced Glutathione, Glutathione S-transferase together with GSH/GSSG ratio between neuro -intoxicated, protected and therapeutically treated rat pups compared to healthy control

\begin{tabular}{|c|c|c|c|c|c|c|c|c|}
\hline Parameter & Group & $\mathrm{N}$ & Min & Max & Mean \pm S.D. & Percent Change & $P$ value $^{a}$ & $P$ value $^{\mathrm{b}}$ \\
\hline \multirow[t]{4}{*}{ LPO (U\ml) } & Control & 10 & 2.70 & 5.00 & $3.68 \pm 0.84$ & 100.00 & & 0.001 \\
\hline & VPA & 10 & 3.10 & 3.90 & $3.52 \pm 0.24$ & 95.65 & 0.573 & \\
\hline & VPA-CUR & 10 & 1.40 & 3.40 & $2.46 \pm 0.55^{c}$ & 66.73 & 0.001 & \\
\hline & CUR & 10 & 1.40 & 3.70 & $2.56 \pm 0.82^{c}$ & 69.57 & 0.007 & \\
\hline \multirow[t]{4}{*}{ GSSG (pg/ml) } & Control & 10 & 65.00 & 125.00 & $92.50 \pm 23.24$ & 100.00 & & 0.001 \\
\hline & VPA & 10 & 150.00 & 310.00 & $225.00 \pm 51.91^{c}$ & 243.24 & 0.001 & \\
\hline & VPA-CUR & 10 & 225.00 & 460.00 & $345.00 \pm 81.99^{c}$ & 372.97 & 0.001 & \\
\hline & CUR & 10 & 100.00 & 180.00 & $138.50 \pm 21.48$ & 149.73 & 0.001 & \\
\hline \multirow[t]{4}{*}{ GSH (pg\ml) } & Control & 10 & 7104.06 & 9134.06 & $8016.97 \pm 638.64$ & 100.00 & & 0.001 \\
\hline & VPA & 10 & 3506.25 & 5417.81 & $4397.66 \pm 557.53^{c}$ & 54.85 & 0.001 & \\
\hline & VPA-CUR & 10 & 4419.06 & 6040.94 & $5099.31 \pm 485.93^{c}$ & 63.61 & 0.001 & \\
\hline & CUR & 10 & 6825.00 & 9638.75 & $8190.53 \pm 948.88$ & 102.16 & 0.637 & \\
\hline \multirow[t]{4}{*}{ GSTs (mU\ml) } & Control & 10 & 8.50 & 20.50 & $15.35 \pm 3.98$ & 100.00 & & 0.001 \\
\hline & VPA & 10 & 11.60 & 18.40 & $13.84 \pm 2.00$ & 90.19 & 0.304 & \\
\hline & VPA-CUR & 10 & 8.50 & 17.00 & $12.74 \pm 2.74$ & 83.00 & 0.105 & \\
\hline & CUR & 10 & 5.50 & 17.00 & $11.57 \pm 3.78^{c}$ & 75.37 & 0.043 & \\
\hline \multirow[t]{4}{*}{ GSH/GSSG } & Control & 10 & 59.15 & 140.52 & $92.59 \pm 27.69$ & 100.00 & & 0.001 \\
\hline & VPA & 10 & 13.87 & 31.68 & $20.54 \pm 5.53^{c}$ & 22.19 & 0.001 & \\
\hline & VPA-CUR & 10 & 9.61 & 22.22 & $15.64 \pm 4.24^{c}$ & 16.89 & 0.001 & \\
\hline & CUR & 10 & 47.43 & 87.58 & $60.33 \pm 11.63^{c}$ & 65.16 & 0.005 & \\
\hline
\end{tabular}

${ }^{a} P$ value between control group and other groups

${ }^{\mathrm{b}} P$ value between all groups

${ }^{c}$ Indicates there is significant difference between the group and control at 0.05 level 
Table 4 Pearson Correlations between the measured parameters

\begin{tabular}{|c|c|c|c|}
\hline Parameters & $\begin{array}{l}\text { R (Person } \\
\text { Correlation) }\end{array}$ & Sig. & \\
\hline Started weight $(\mathrm{g}) \sim$ Final weight $(\mathrm{g})$ & $0.641^{* *}$ & 0.001 & $P^{a}$ \\
\hline Started weight $(\mathrm{g}) \sim$ Weight Gained & $0.494^{* *}$ & 0.001 & $\mathrm{P}^{\mathrm{a}}$ \\
\hline Started weight $(\mathrm{g}) \sim$ Brain weight $(\mathrm{g})$ & $0.652^{* *}$ & 0.001 & $P^{a}$ \\
\hline Started weight (g) Opening eyes after (Days) & $0.313^{*}$ & 0.049 & $P^{a}$ \\
\hline Started weight $(\mathrm{g}) \sim$ Glutamate/Glutamin Ratio & $0.322^{*}$ & 0.043 & $p^{a}$ \\
\hline Started weight $(\mathrm{g}) \sim \mathrm{GSH}(\mathrm{mmol} / \mathrm{L})$ & $-0.438^{* *}$ & 0.005 & $N^{b}$ \\
\hline Started weight $(\mathrm{g}) \sim \mathrm{GSSG}(\mathrm{pg} / \mathrm{ml})$ & $0.765^{* *}$ & 0.001 & $p^{a}$ \\
\hline Started weight $(\mathrm{g}) \sim \mathrm{GSH}(\mathrm{pg} \backslash \mathrm{ml})$ & $-0.438^{* *}$ & 0.005 & $N^{b}$ \\
\hline Started weight $(\mathrm{g}) \sim \mathrm{GSH}+\mathrm{GSSG}$ & $-0.408^{* *}$ & 0.009 & $\mathrm{~N}^{\mathrm{b}}$ \\
\hline Started weight $(\mathrm{g}) \sim \mathrm{GSH} / \mathrm{GSSG}$ & $-0.479^{* *}$ & 0.002 & $N^{b}$ \\
\hline Final weight $(\mathrm{g}) \sim$ Weight Gained & $0.984^{* *}$ & 0.001 & $p^{a}$ \\
\hline Final weight $(\mathrm{g}) \sim$ Brain weight $(\mathrm{g})$ & $0.887^{* *}$ & 0.001 & $p^{a}$ \\
\hline Final weight $(\mathrm{g}) \sim \mathrm{LPO}(\mathrm{U} \backslash \mathrm{ml})$ & $-0.371^{*}$ & 0.019 & $N^{b}$ \\
\hline Final weight $(\mathrm{g}) \sim \mathrm{GSSG}(\mathrm{pg} / \mathrm{ml})$ & $0.390^{*}$ & 0.013 & $p^{a}$ \\
\hline Weight Gained Brain weight (g) & $0.853^{* *}$ & 0.001 & $p^{a}$ \\
\hline Weight Gained LPO (U\ml) & $-0.353^{*}$ & 0.025 & $N^{b}$ \\
\hline Brain weight $(\mathrm{g}) \sim \mathrm{LPO}(\mathrm{U} \backslash \mathrm{ml})$ & $-0.313^{*}$ & 0.049 & $N^{b}$ \\
\hline Brain weight $(\mathrm{g})$ GSSG (pg/ml) & $0.369^{*}$ & 0.019 & $p^{a}$ \\
\hline Opening eyes after (Days) GSH (mmol/L) & $-0.326^{*}$ & 0.04 & $N^{b}$ \\
\hline Opening eyes after (Days) GSH (pg\ml) & $-0.326^{*}$ & 0.04 & $N^{b}$ \\
\hline Opening eyes after (Days) GSH + GSSG & $-0.322^{*}$ & 0.043 & $N^{b}$ \\
\hline IL-6 (pg\ml) Glutamin (pmol\ml) & $0.377^{*}$ & 0.017 & $p^{a}$ \\
\hline IL-6 (pg\ml) Glutamate (nmol\ml) & $0.322^{*}$ & 0.043 & $p^{a}$ \\
\hline IL-6 (pg\ml) LPO (U\ml) & $0.318^{*}$ & 0.045 & $P^{a}$ \\
\hline IFN-g (pg\ml) GSTs (mU\ml) & $0.588^{* *}$ & 0.001 & $P^{a}$ \\
\hline IFN-g (pg\ml) Glutamin (pmol\ml) & $0.541^{* *}$ & 0.001 & $P^{a}$ \\
\hline IFN-g (pg\ml) Glutamate (nmol\ml) & $0.502^{* *}$ & 0.001 & $p^{a}$ \\
\hline 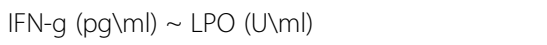 & $0.523^{* *}$ & 0.001 & $\mathrm{p}^{\mathrm{a}}$ \\
\hline CYP450 (ng\ml) GSTs (mU\ml) & $-0.347^{*}$ & 0.028 & $N^{b}$ \\
\hline 5HT (ng\ml) GSSG (pg/ml) & $-0.352^{*}$ & 0.026 & $N^{b}$ \\
\hline GSTs (mU\ml) Glutamin (pmolıml) & $0.597^{* *}$ & 0.001 & $p^{a}$ \\
\hline GSTs $(\mathrm{mU} \backslash \mathrm{ml}) \sim$ Glutamate $(\mathrm{nmol} / \mathrm{ml})$ & $0.451^{* *}$ & 0.004 & $p^{a}$ \\
\hline GSTs (mU\ml) LPO (U\ml) & $0.650^{* *}$ & 0.001 & $p^{a}$ \\
\hline $\begin{array}{l}\text { Glutamin }(p m o / \backslash m l) \sim ~ G l u t a m a t e \\
(\mathrm{nmol} / \mathrm{ml})\end{array}$ & $0.635^{* *}$ & 0.001 & $P^{a}$ \\
\hline $\begin{array}{l}\text { Glutamin }(\mathrm{pmo} / \mathrm{ml}) \sim \text { Glutamate/ } \\
\text { Glutamin Ratio }\end{array}$ & $-0.414^{* *}$ & 0.008 & $N^{b}$ \\
\hline Glutamin (pmol\ml) LPO (U\ml) & $0.722^{* *}$ & 0.001 & $p^{a}$ \\
\hline $\begin{array}{l}\text { Glutamate (nmol\ml) Glutamate/ } \\
\text { Glutamin Ratio }\end{array}$ & $0.435^{* *}$ & 0.005 & $P^{a}$ \\
\hline Glutamate (nmol\ml) LPO (U\ml) & $0.678^{* *}$ & 0.001 & $P^{a}$ \\
\hline Glutamate/Glutamin Ratio GSSG (pg/ml) & $0.337^{*}$ & 0.033 & $p^{a}$ \\
\hline GSH (mmol/L) GSSG (pg/ml) & $-0.684^{* *}$ & 0.001 & $N^{b}$ \\
\hline GSH $(\mathrm{mmol} / \mathrm{L}) \sim \mathrm{GSH}(\mathrm{pg} \backslash \mathrm{ml})$ & $1.000^{* *}$ & 0.001 & $P^{a}$ \\
\hline
\end{tabular}

Table 4 Pearson Correlations between the measured parameters (Continued)

\begin{tabular}{llll}
\hline GSH $(\mathrm{mmol} / \mathrm{L}) \sim \mathrm{GSH}+\mathrm{GSSG}$ & $0.999^{* *}$ & 0.001 & $\mathrm{p}^{\mathrm{a}}$ \\
$\mathrm{GSH}(\mathrm{mmol} / \mathrm{L}) \sim \mathrm{GSH} / \mathrm{GSSG}$ & $0.819^{* *}$ & $0.001 \mathrm{p}^{\mathrm{a}}$ \\
$\mathrm{GSSG}(\mathrm{pg} / \mathrm{ml}) \sim \mathrm{GSH}(\mathrm{pg} \backslash \mathrm{ml})$ & $-0.684^{* *}$ & $0.001 \mathrm{~N}^{\mathrm{b}}$ \\
$\mathrm{GSSG}(\mathrm{pg} / \mathrm{ml}) \sim \mathrm{GSH}+\mathrm{GSSG}$ & $-0.651^{* *}$ & $0.001 \mathrm{~N}^{\mathrm{b}}$ \\
$\mathrm{GSSG}(\mathrm{pg} / \mathrm{ml}) \sim \mathrm{GSH} / \mathrm{GSSG}$ & $-0.816^{* *}$ & $0.001 \mathrm{~N}^{\mathrm{b}}$ \\
$\mathrm{GSH}(\mathrm{pg} \backslash \mathrm{ml}) \sim \mathrm{GSH}+\mathrm{GSSG}$ & $0.999^{* *}$ & $0.001 \mathrm{p}^{\mathrm{a}}$ \\
$\mathrm{GSH}(\mathrm{pg} \backslash \mathrm{ml}) \sim \mathrm{GSH} / \mathrm{GSSG}$ & $0.819^{* *}$ & $0.001 \mathrm{p}^{\mathrm{a}}$ \\
$\mathrm{GSH}+\mathrm{GSSG} \sim \mathrm{GSH} / \mathrm{GSSG}$ & $0.803^{* *}$ & $0.001 \mathrm{P}^{\mathrm{a}}$ \\
\hline
\end{tabular}

${ }^{* *}$ Correlation is significant at the 0.01 level.

*Correlation is significant at the 0.05 level.

aPositive Correlation.

${ }^{\mathrm{b}}$ Negative Correlation

blocking phosphorylation of the inhibitory factor I-kappa B (IKB) [20]. VPA is generally used in the treatment of epilepsy, but recently, it has been found to be effective in the treatment of oncolytic herpes simplex virus (oHSV) infection, as this drug can inhibit the expression of IFN- $\beta$ and the IFN-mediated proteins STAT1 and PKR in infected cells [21]. This could support our results showing a significant decrease of IFN- $\gamma$ in VPA-exposed pups. Additionally, the remarkable decrease in this parameter in curcumintreated pups may be due to the anti-inflammatory action of curcumin, which causes inhibition of production of cytokines, such as interferon- $\gamma$, due to suppression of the Janus kinase (JAK)-STAT signaling cascade [22]. Cytochrome P450 was found to be increased in VPA-exposed pups while a slight decrease was observed in VPA-CUR and CUR groups, as shown in Table 2. The cytochrome P450 enzymes are the major catalysts involved in the metabolism of many psychoactive drugs in the brain. The significant increase in CYT-P450 in VPA-exposed pups could be due to the availability of VPA as a substrate. Curcumin, a good antioxidant, was slightly effective in decreasing the activity of CYT-P450 [23]. The role of CYT-P450 in the metabolism of VPA can also be explained through non-significant changes in the concentration of lipid peroxides as markers of oxidative stress, as demonstrated in Table 3. The same table demonstrates the antioxidant effects of curcumin, as shown by significant decreases of lipid peroxides in VPACUR and CUR groups compared to the VPA group. An unexpected finding of the present study is that VPA does not induce elevation of lipid peroxides as markers of oxidative stress. This finding could be attributed to the fact that VPA is an anti-epileptic drug that is designed to have the least toxic effects on treated patients. The significant decrease in lipid peroxide levels in VPA-CUR and CUR groups compared to the control group is consistent with various models posed by several authors, which proves that curcumin is a good antioxidant that inhibits lipid peroxidation [24]. 

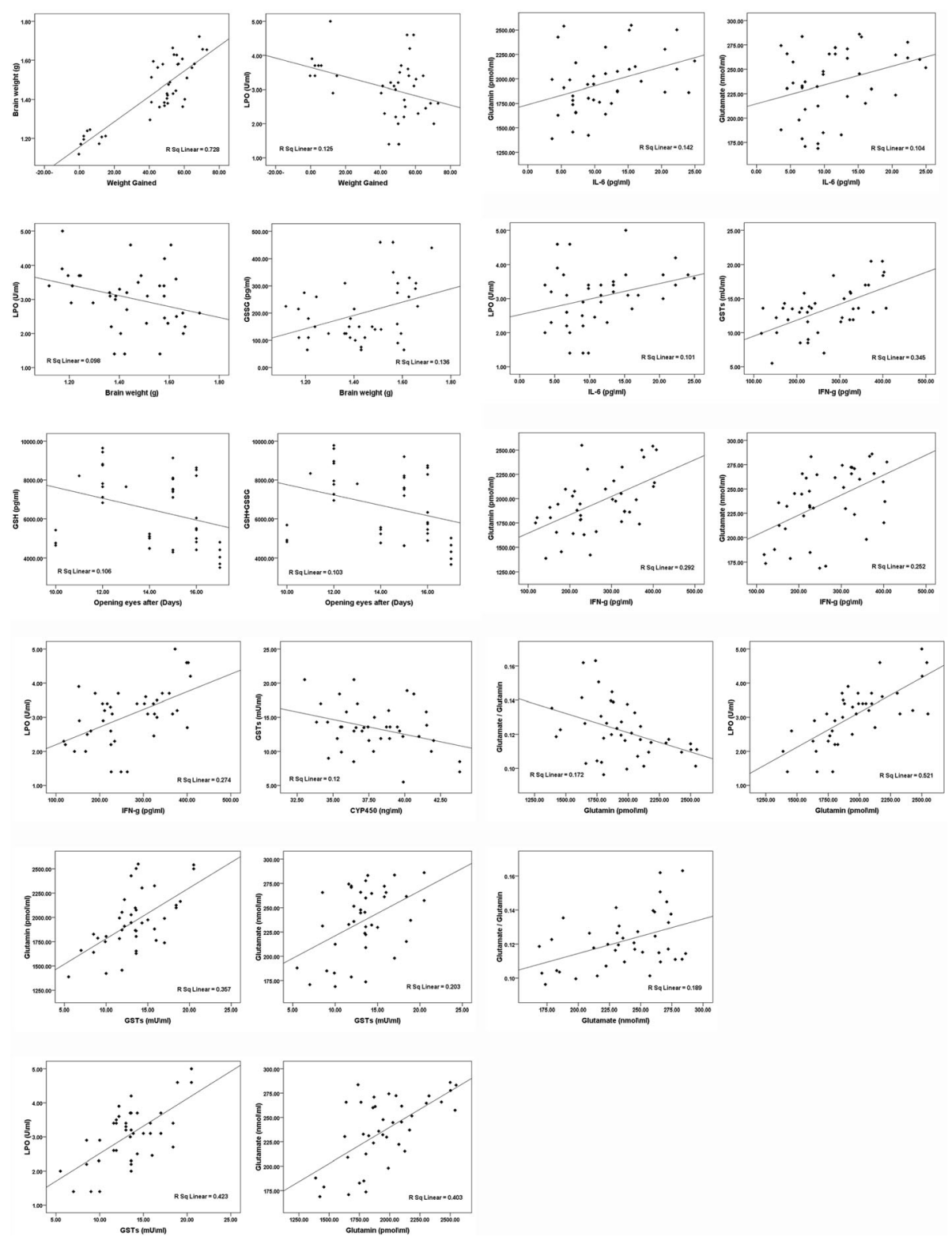

Fig. 2 Correlation between all parameters with best fit line curve

Glutathione-S-transferases (GSTs) play a key role in enzymatic detoxification and were found to be $10.19 \%$ lower in the VPA group than in the control group (Table 3), which is due to the neurotoxic effect of VPA through insufficient conjugation of electrophiles and detoxification of the reactive species, as previously described by Chaudhary \& Parvez, in the cerebellum and cerebral cortex of the rat brain [25]. Rats fed dietary curcumin were found to have decreased hepatic GST activity compared to controls because of competitive enzyme inhibition by the curcumin molecule [26]. This could explain the remarkable decrease of GST in the VPA-CUR and CUR groups.
Table 2 shows the non-significant decreased level of serotonin in the VPA group compared to the control group. On the other hand, an increase in serotonin in the CUR group was observed compared to the control, the VPA and the VPA-CUR groups, with values of $6.78,12.56$ and $15.5 \%$, respectively. This is not consistent with a previous study, in which increased levels of serotonin were found in the brains of rats that had been prenatally exposed to VPA in association with disrupted sleep/awake rhythms [27]. Aside from the well-known deficiency in serotonergic neurotransmission as a pathophysiological correlate of autism, recent evidence points to the pivotal 

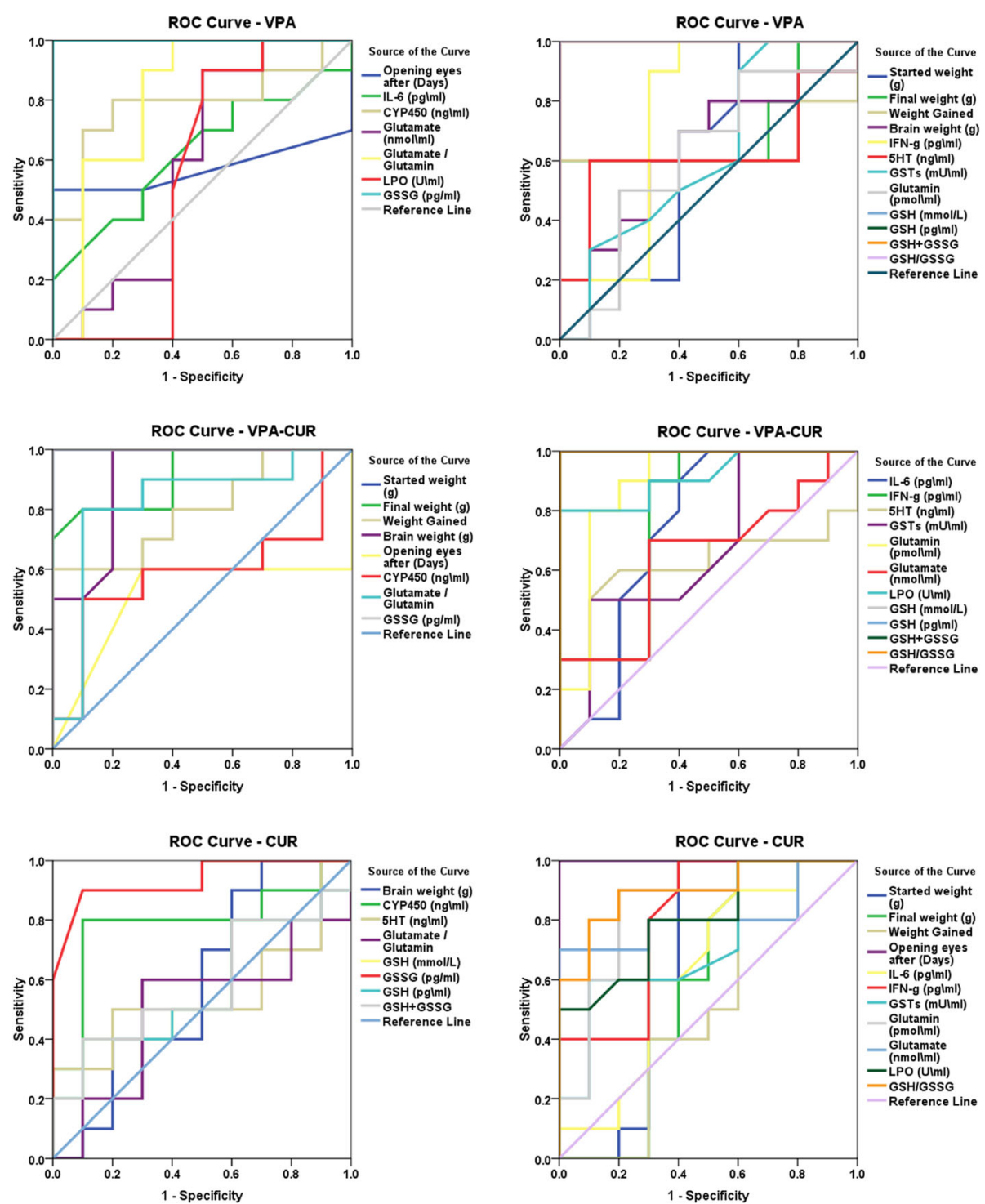

Fig. 3 ROC Curve of all parameters for all groups

role of increased glutamate receptor activation as well. While the present study demonstrates a non-significant decrease in brain serotonin of VPA-exposed rats, a remarkable elevation in brain glutamate was recorded. A hypothesis integrating current concepts of neurotransmission and hypothalamus-pituitary-adrenal (HPA) axis dysregulation with findings on immunological alterations was proposed by Müller and Schwarz [28]. Immune activation, including increased production of pro-inflammatory cytokines, has repeatedly been described in mild depression. Pro-inflammatory cytokines such as IL-2 and IL-6 activate the tryptophan- and serotonin-degrading enzyme indole amine 2,3-dioxygenase (IDO). Based on this hypothesis, the increase in IL- 6 reported in the present study can be related to the decrease in serotonin levels. A VPA-exposed developmental rodent model in the present study may show persistent autistic features that present biochemically as low serotonin and high glutamate levels [29].

Glutamate is an excitatory neurotransmitter that is usually transported from neurons to astrocytes in order to be buffered through the formation of glutamine; the glutamate/glutamine ratio can be a useful marker for the decrease of excitotoxicity. Table 3 shows the non-significant elevation of glutamate along with the unchanged glutamine and glutamate/glutamine ratio in the VPA-exposed rats compared to the control group. This is supported by the previous work of Bristot Silvestrin et al. [30], which reported unaltered glutamate uptake in 15 day old rats that were prenatally exposed to VPA and showed a $160 \%$ increase at an age of 120 days. The anti-excitotoxicity effect of curcumin, presented as a much lower glutamate level in cur-treated rats compared to VPA-exposed rats, and 
Table 5 ROC Curve of weight gain, brain weight and age of eye opening between neuro-intoxicated, protected and therapeutically treated rat pups compared to healthy control

\begin{tabular}{llllll}
\hline Parameters & Groups & $\begin{array}{l}\text { Area under } \\
\text { the curve }\end{array}$ & $\begin{array}{l}\text { Cutoff } \\
\text { value }\end{array}$ & Sensitivity \% & Specificity $\%$ \\
\hline Started & VPA & 0.600 & 18.900 & $100.0 \%$ & $40.0 \%$ \\
weight (g) & VPA-CUR & 1.000 & 22.250 & $100.0 \%$ & $100.0 \%$ \\
& CUR & 0.670 & 18.250 & $100.0 \%$ & $60.0 \%$ \\
Final & VPA & 0.700 & 25.450 & $60.0 \%$ & $100.0 \%$ \\
weight (g) & VPA-CUR & 0.915 & 77.550 & $80.0 \%$ & $90.0 \%$ \\
& CUR & 0.585 & 71.300 & $100.0 \%$ & $40.0 \%$ \\
Weight & VPA & 0.640 & 8.700 & $60.0 \%$ & $100.0 \%$ \\
Gained & VPA-CUR & 0.800 & 60.200 & $60.0 \%$ & $100.0 \%$ \\
& CUR & 0.530 & 52.700 & $100.0 \%$ & $40.0 \%$ \\
\multirow{2}{*}{ Brain } & VPA & 0.640 & 1.415 & $80.0 \%$ & $50.0 \%$ \\
weight (g) & VPA-CUR & 0.905 & 1.477 & $100.0 \%$ & $80.0 \%$ \\
& CUR & 0.590 & 1.364 & $90.0 \%$ & $40.0 \%$ \\
\multirow{2}{*}{$\begin{array}{l}\text { Opening } \\
\text { eyes after }\end{array}$} & VPA & 0.570 & 16.500 & $50.0 \%$ & $100.0 \%$ \\
(Days) & VPA-CUR & 0.510 & 15.500 & $60.0 \%$ & $70.0 \%$ \\
& CUR & 1.000 & 14.000 & $100.0 \%$ & $100.0 \%$ \\
\hline
\end{tabular}

even the control group, can be easily related to its protective effect against glutamate excitotoxicity [31].

GSH was significantly lower in VPA-exposed rat pups (7 days old), compared to the control group (Table 3) This is consistent with the recent study by Bristot Silvestrin et al. [30], which recorded unaltered GSH levels in 15day-old rats that were prenatally exposed to VPA. This can be related to the non-significant elevation in glutamate reported in the present study. The unchanged GSH and glutamate levels recorded in the present study do not contradict the use of VPA-exposed rats as rodent models of autism. This opinion can be supported with the previously mentioned significant impairment of both parameters in 120-day-old rats that were exposed to VPA during pregnancy. The neurotoxic effect of VPA, along with the neuro-therapeutic and antioxidant effects of curcumin can be observed together in Table 3.9. A highly significant decrease in GSSG in VPA-exposed rats reflects the impairment of total antioxidant and glutathione status in this group of animals. GSSG, as an oxidized form of glutathione, can be easily converted to GSH by glutathione reductase, and hence, a lower concentration can easily lead to low GSH. In our study, VPA-exposed rats were under stressful conditions, so the unexpected increase of GSSG in valproate-treated animals that were also treated with curcumin, is supported by the previous study by Hagl et al. [32], who reported that when under non-stressful conditions, curcumin induces the synthesis of GSH and many detoxifying enzymes (as shown in group IV). This might also be attributed to the low absorption and quick
Table 6 ROC Curve of Interleukin-6, Interferon Gamma, cytochrome P450, Serotonin, Glutamine, Glutamate together with Glutamate/Glutamine ratio in neuro-intoxicated, protected and therapeutically treated rat pups compared to healthy control

\begin{tabular}{|c|c|c|c|c|c|}
\hline Parameters & Groups & $\begin{array}{l}\text { Area under } \\
\text { the curve }\end{array}$ & $\begin{array}{l}\text { Cutoff } \\
\text { value }\end{array}$ & Sensitivity \% & Specificity \% \\
\hline \multirow{3}{*}{$\begin{array}{l}\text { IL-6 } \\
\text { (pg\ml) }\end{array}$} & VPA & 0.625 & 9.832 & $80.0 \%$ & $40.0 \%$ \\
\hline & $\begin{array}{l}\text { VPA- } \\
\text { CUR }\end{array}$ & 0.740 & 11.165 & $90.0 \%$ & $60.0 \%$ \\
\hline & CUR & 0.635 & 12.945 & $80.0 \%$ & $50.0 \%$ \\
\hline \multirow{3}{*}{$\begin{array}{l}\text { IFN-y } \\
(p g \backslash m l)\end{array}$} & VPA & 0.750 & 318.225 & $90.0 \%$ & $70.0 \%$ \\
\hline & $\begin{array}{l}\text { VPA- } \\
\text { CUR }\end{array}$ & 0.780 & 327.520 & $90.0 \%$ & $70.0 \%$ \\
\hline & CUR & 0.805 & 365.885 & $100.0 \%$ & $60.0 \%$ \\
\hline \multirow{3}{*}{$\begin{array}{l}\text { CYP450 } \\
\text { (ng\ml) }\end{array}$} & VPA & 0.790 & 37.085 & $80.0 \%$ & $80.0 \%$ \\
\hline & $\begin{array}{l}\text { VPA- } \\
\text { CUR }\end{array}$ & 0.590 & 37.471 & $50.0 \%$ & $90.0 \%$ \\
\hline & CUR & 0.790 & 37.630 & $80.0 \%$ & $90.0 \%$ \\
\hline \multirow{3}{*}{$\begin{array}{l}5 \mathrm{HT} \\
\text { (ng\ml) }\end{array}$} & VPA & 0.620 & 137.220 & $60.0 \%$ & $90.0 \%$ \\
\hline & $\begin{array}{l}\text { VPA- } \\
\text { CUR }\end{array}$ & 0.625 & 140.965 & $60.0 \%$ & $80.0 \%$ \\
\hline & CUR & 0.550 & 157.750 & $50.0 \%$ & $80.0 \%$ \\
\hline \multirow{3}{*}{$\begin{array}{l}\text { GSTs } \\
\text { (mU\ml) }\end{array}$} & VPA & 0.620 & 17.100 & $90.0 \%$ & $40.0 \%$ \\
\hline & $\begin{array}{l}\text { VPA- } \\
\text { CUR }\end{array}$ & 0.675 & 12.450 & $50.0 \%$ & $90.0 \%$ \\
\hline & CUR & 0.730 & 12.450 & $60.0 \%$ & $90.0 \%$ \\
\hline \multirow{3}{*}{$\begin{array}{l}\text { Glutamin } \\
\text { (pmo/Iml) }\end{array}$} & VPA & 0.610 & 2365.295 & $90.0 \%$ & $40.0 \%$ \\
\hline & $\begin{array}{l}\text { VPA- } \\
\text { CUR }\end{array}$ & 0.890 & 1984.715 & $90.0 \%$ & $80.0 \%$ \\
\hline & CUR & 0.840 & 2007.865 & $90.0 \%$ & $80.0 \%$ \\
\hline \multirow{3}{*}{$\begin{array}{l}\text { Glutamate } \\
\text { (nmol/ml) }\end{array}$} & VPA & 0.590 & 244.955 & $90.0 \%$ & $50.0 \%$ \\
\hline & $\begin{array}{l}\text { VPA- } \\
\text { CUR }\end{array}$ & 0.645 & 234.870 & $70.0 \%$ & $70.0 \%$ \\
\hline & CUR & 0.810 & 213.790 & $70.0 \%$ & $100.0 \%$ \\
\hline \multirow{3}{*}{$\begin{array}{l}\text { Glutamate/ } \\
\text { Glutamin } \\
\text { ratio }\end{array}$} & VPA & 0.810 & 0.111 & $100.0 \%$ & $60.0 \%$ \\
\hline & $\begin{array}{l}\text { VPA- } \\
\text { CUR }\end{array}$ & 0.820 & 0.122 & $80.0 \%$ & $90.0 \%$ \\
\hline & CUR & 0.500 & 0.115 & $60.0 \%$ & $70.0 \%$ \\
\hline
\end{tabular}

elimination of curcumin from the body. Hagl et al. proved that low bioavailability of curcumin can be ameliorated through administration with secondary plant compounds, micronization and micellation, which might help to increase its therapeutic potency [32].

Tables 5, 6 and 7 present the ROC curve parameters of all measured variables from all test groups. It is readily apparent that while some parameters show effectiveness as biomarkers for VPA neurotoxicity, others are good to excellent markers for CUR therapeutic and/or antioxidant effects. The postnatal growth and maturation markers presented by weight gain, brain weight and eye opening demonstrated AUC ranges between 0.7 and 1, which support 
Table 7 ROC Curve of Lipid Peroxide, Oxidized Glutathione, Reduced Glutathione, Glutathione S-transferase together with GSH/GSSG ratio between neuro-intoxicated, protected and therapeutically treated rat pups compared to healthy control

\begin{tabular}{|c|c|c|c|c|c|}
\hline Parameters & Groups & $\begin{array}{l}\text { Area under } \\
\text { the curve }\end{array}$ & $\begin{array}{l}\text { Cutoff } \\
\text { value }\end{array}$ & Sensitivity \% & Specificity \% \\
\hline \multirow{3}{*}{$\begin{array}{l}\text { LPO } \\
\text { (U\ml) }\end{array}$} & VPA & 0.545 & 3.250 & $90.0 \%$ & $50.0 \%$ \\
\hline & $\begin{array}{l}\text { VPA- } \\
\text { CUR }\end{array}$ & 0.915 & 2.650 & $80.0 \%$ & $100.0 \%$ \\
\hline & CUR & 0.805 & 3.150 & $80.0 \%$ & $70.0 \%$ \\
\hline \multirow{3}{*}{$\begin{array}{l}\text { GSH } \\
(\mathrm{mmol} / \mathrm{L})\end{array}$} & VPA & 1.000 & 200.350 & $100.0 \%$ & $100.0 \%$ \\
\hline & $\begin{array}{l}\text { VPA- } \\
\text { CUR }\end{array}$ & 1.000 & 210.320 & $100.0 \%$ & $100.0 \%$ \\
\hline & CUR & 0.570 & 278.195 & $40.0 \%$ & $90.0 \%$ \\
\hline \multirow{3}{*}{$\begin{array}{l}\text { GSSG } \\
(\mathrm{pg} / \mathrm{ml})\end{array}$} & VPA & 1.000 & 137.500 & $100.0 \%$ & $100.0 \%$ \\
\hline & $\begin{array}{l}\text { VPA- } \\
\text { CUR }\end{array}$ & 1.000 & 175.000 & $100.0 \%$ & $100.0 \%$ \\
\hline & CUR & 0.935 & 117.500 & $90.0 \%$ & $90.0 \%$ \\
\hline \multirow{3}{*}{$\begin{array}{l}\text { GSH } \\
(p g \backslash m l)\end{array}$} & VPA & 1.000 & 6260.938 & $100.0 \%$ & $100.0 \%$ \\
\hline & $\begin{array}{l}\text { VPA- } \\
\text { CUR }\end{array}$ & 1.000 & 6572.500 & $100.0 \%$ & $100.0 \%$ \\
\hline & CUR & 0.570 & 8693.594 & $40.0 \%$ & $90.0 \%$ \\
\hline \multirow{3}{*}{$\begin{array}{l}\text { GSH + } \\
\text { GSSG }\end{array}$} & VPA & 1.000 & 6435.938 & $100.0 \%$ & $100.0 \%$ \\
\hline & $\begin{array}{l}\text { VPA- } \\
\text { CUR }\end{array}$ & 1.000 & 6762.500 & $100.0 \%$ & $100.0 \%$ \\
\hline & CUR & 0.580 & 8798.594 & $40.0 \%$ & $90.0 \%$ \\
\hline \multirow{3}{*}{$\begin{array}{l}\text { GSH/ } \\
\text { GSSG }\end{array}$} & VPA & 1.000 & 45.417 & $100.0 \%$ & $100.0 \%$ \\
\hline & $\begin{array}{l}\text { VPA- } \\
\text { CUR }\end{array}$ & 1.000 & 40.685 & $100.0 \%$ & $100.0 \%$ \\
\hline & CUR & 0.900 & 71.255 & $90.0 \%$ & $80.0 \%$ \\
\hline
\end{tabular}

their use as markers for VPA neurotoxicity and curcumin therapeutic potency. IL-6 shows smaller AUC values compared to IFN- $\gamma$, which suggests that the latter is a good marker for VPA toxicity and curcumin therapeutic and antioxidant effects. Lipid peroxides and CYT P450 both demonstrate a satisfactory AUC, which shows that both can be used to test the efficacy of the curcumin antioxidant effect. Serotonin, GST, glutamate and glutamine all showed relatively poor potency as markers for VPA neurotoxicity and were good markers for curcumin efficacy. Conversely, GSSG and GSH both show a high predictive value that can be used as markers of VPA neurotoxicity and of curcumin's therapeutic effect. The increase in GSSG in valproatetreated animals that were also treated with curcumin was unexpected but is supported in the previous study by Reyes et al. (2013), who reported that under non-stress conditions, curcumin induces the synthesis of GSH and of many detoxifying and cytoprotective enzymes. Based on this, our data suggest that pretreatment with curcumin may have more protective effects than therapeutic antioxidant effects but still demonstrates therapeutic effects in ameliorating IL-6, INF- $\gamma$, LOP, GST,5-HT and GSH.

\section{Conclusion}

To summarize, this study shows evidence of the postnatal therapeutic role of curcumin in improving most of the impaired parameters in VPA-induced rodent models with persistent autistic features. The mechanism of action underlying the therapeutic effects of curcumin should be investigated in the near future. Studies of the protective effects of curcumin are also recommended.

\section{Additional file}

Additional file 1: CAM curcumine data. (XLSX $50 \mathrm{~kb}$ )

\section{Acknowledgments}

This research project was supported by a grant from the research center of the Center for Female Scientific and Medical Colleges at King Saud University.

Funding

Research center of the Center for Female Scientific and Medical Colleges at King Saud University.

Availability of data and material

Data is available as supplementary excel sheet (Additional file 1).

\section{Authors' contributions}

MA: Performed the practical work; RS: Co-drafted the manuscript and designed the illustrated experimental chart; MS: Supervised the experimental work related to VPA dosage; LA: Revised the manuscript and did the statistical analysis; AE: Suggested the topic and co-drafted the manuscript. All authors read and approved the final manuscript.

Competing interests

The authors declare that they have no competing interests.

Consent for publication

Not applicable.

\section{Ethics approval and consent to participate}

This work was approved by the Ethical Committee of Science College at King Saud University (approval no KSU-IRB008E.)

\section{Publisher's Note}

Springer Nature remains neutral with regard to jurisdictional claims in published maps and institutional affiliations.

\section{Author details}

${ }^{1}$ Department of Biochemistry, Science College, King Saud University, Riyadh, Saudi Arabia. ${ }^{2}$ Department of Zoology, Science College, King Saud University, Riyadh, Saudi Arabia. ${ }^{3}$ Department of Physiology, Faculty of Medicine, King Saud University, Riyadh, Saudi Arabia. ${ }^{4}$ Central Laboratory, Female Center for Medical Studies and Scientific Section, Riyadh, Saudi Arabia. ${ }^{5}$ Autism Research and Treatment Center, Riyadh, Saudi Arabia. ${ }^{6}$ Shaik AL-Amodi Autism Research Chair, King Saud University, Riyadh, Saudi Arabia.

Received: 24 February 2017 Accepted: 28 April 2017

Published online: 10 May 2017

\section{References}

1. Van der Staay FJ, Arndt SS, Nordquist RE. Evaluation of animal models of neurobehavioral disorders. Behav Brain Funct. 2009:5:11.

2. Ergaz Z, Weinstein-Fudim L, Ornoy A. Genetic and non-genetic animal models for autism spectrum disorders (ASD) Reprod. Toxicology. 2016:64:116-40.

3. Kazlauskas N, Campolongo M, Lucchina L, Zappala C, Depino AM. Postnatal behavioral and inflammatory alterations in female pupsprenatally exposed to valproic acid. Psychoneuroendocrinology. 2016;72:11-21. 
4. Kim JW, Seung H, Kim KC, Gonzales EL, Oh HA, Yang SM, Ko MJ, Han SH, Banerjee $\mathrm{S}$, Shin CY. Agmatine rescues autistic behaviors in the valproic acidinduced animal model of autism. Neuropharmacology. 2017;113(Pt A):71-81.

5. Christensen J, Grønborg TK, Sørensen MJ, Schendel D, Parner ET, Pedersen $\mathrm{LH}$, Vestergaard M. Prenatal valproate exposure and risk of autism spectrum disorders and childhood autism. JAMA. 2013:309(16):1696-703.

6. Kim KC, Kim P, Go HS, Choi CS, Yang SI, Cheong JH, Shin CY, Ko KH. The critical period of valproate exposure to induce autistic symptoms in Sprague-Dawley rats. Toxicol Lett. 2011;201:137-42.

7. Ghodke-Puranik Y, Thorn CF, Lamba JK, Leeder JS, Song W, Birnbaum AK, Klein TE. Valproic acid pathway: pharmacokinetics and pharmacodynamics. Pharmacogenet Genomics. 2013;23(4):236-41.

8. Johannessen CU, Johannessen SI. Valproate: past, present, and future. CNS Drug Rev. 2003;9:199-216.

9. Bromley RL, Baker GA, Meador KJ. Cognitive abilities and behaviour of children exposed to antiepileptic drugs in utero. Curr Opin Neurol. 2009;22:162-6.

10. McVearry KM, Gaillard WD, VanMeter J, Meador KJ. A prospective study of cognitive fluency and originality in children exposed in utero to carbamazepine, lamotrigine, or valproate monotherapy. Epilepsy Behav. 2009;16:609-16.

11. Meador KJ, Baker GA, Browning N, Cohen MJ, Clayton-Smith J, Kalayjian LA, Kanner A, Liporace JD, Pennell PB, Privitera M, Loring DW. NEAD Study Group Foetal antiepileptic drug exposure and verbal versus non-verbal abilities at three years of age. Brain. 2011;134(Pt 2):396-404.

12. Mythri RB, Bharath MM. Curcumin: a potential neuroprotective agent in Parkinson's disease. Curr Pharm Des. 2012;18(1):91-9.

13. Aggarwal BB, Harikumar KB. Potential therapeutic effects of curcumin, the anti-inflammatory agent, against neurodegenerative, cardiovascular, pulmonary, metabolic, autoimmune and neoplastic diseases Int. J Biochem Cell Biol. 2009;41(1):40-59.

14. Bhandari R. Kuhad a Neuropsychopharmacotherapeutic efficacy of curcumin in experimental paradigm of autism spectrum disorders. Life Sci. 2015;141:156-69.

15. Schneider T, Przewłocki R. Behavioral alterations in rats prenatally exposed to valproic acid: animal model of autism. Neuropsychopharmacology. 2005; 30(1):80-9.

16. Purwar B, Shrivastava A, Arora N, Saxena AKAY. Effects of Curcumin on the gastric emptying of albino rats. Indian J Physiol Pharmacol. 2012:56(2):168-73.

17. Roullet FI, Lai JK, Foster JA. In utero exposure to valproic acid and autism-a current review of clinical and animal studies. Neurotoxicol Teratol. 2013;36:47-56.

18. Ma J, Liu J, Yu H, Wang Q, Chen Y, Xiang L. Curcumin promotes nerve regeneration and functional recovery in rat model of nerve crush injury. Neurosci Lett. 2013;547:26-31.

19. Erta M, Quintana A, Hidalgo J. Interleukin-6, a major cytokine in the central nervous system. Int J Biol Sci. 2012;8(9):1254-66.

20. Jurenka JS. Anti-inflammatory properties of Curcumin, a major constituent of Curcuma longa: a review of preclinical and clinical research. Altern Med Rev. 2009;14(2):141-53.

21. Otsuki A, et al. Histone deacetylase inhibitors augment antitumor efficacy of herpes-based oncolytic viruses. Mol Ther. 2008;16:1546-55.

22. Kim HY, Park EJ, Joe EH, et al. Curcumin suppresses januskinase-STAT inflammatory signalling through activation of Srchomology 2 domain-containing tyrosine phosphatase 2 in brain microglia. J Immunol. 2003;171:6072-9.

23. Sharma RA, Gescher AJ, Steward WP. Curcumin: the story so far. Eur J Cancer. 2005;41:1955-68.

24. El-Demerdasha FM, Yousef MI, Radwan FM. Ameliorating effect of curcumin on sodium arsenite-induced oxidative damage and lipid peroxidation in different rat organs. Food Chem Toxicol. 2009;47(1):249-54.

25. Chaudhary S, Parvez S. An in vitro approach to assess the neurotoxicityof valproic acid-induced oxidative stress in cerebellumand cerebral cortex of young rats. Neuroscience. 2012;225:258-68.

26. Piper JT, Singhal SS, Salameh M, Torman RT, Awasthi YC, Awasthi S. Mechanisms of anticarcinogenic properties ofcurcumin: the effect of curcumin on glutathione linked detoxificationenzymes in rat liver. Int $J$ Biochem Cell Biol. 1998:30:445-56.

27. Gottfried C, Bambini-Junior V, Baronio D, Zanatta G, Silvestrin RB, Vaccaro T, Riesgo R. In: Fitzgerald M, editor. ISBN: 978-953-51-1021-7, In Tech Valproic acid in autism spectrum disorder: from an environmental risk factor to a reliable animal model, recent advances in autism spectrum disorders, vol. 1; 2013. doi:10.5772/54824.

28. Müller N, Schwarz MJ. The immune-mediated alteration of serotonin and glutamate: towards an integrated view of depression. Mol Psychiatry. 2007;12(11):988-1000.
29. Anderson G, Maes M. Redox regulation and the autistic Spectrum: role of tryptophan Catabolites, Immuno-inflammation, Autoimmunity and the Amygdala. Curr Neuropharmacol. 2014;12(2):148-67.

30. Bristot Silvestrin R, Bambini-Junior V, Galland F, Daniele Bobermim L, Quincozes-Santos A, Torres Abib R, Zanotto C, et al. Animal model of autism induced by prenatal exposure to valproate: altered glutamate metabolism in the hippocampus. Brain Res. 2013;1495:52-60.

31. Wang R, Li YB, Li YH, Xu Y, Wu HL, Li XJ. Curcumin protects against glutamate excitotoxicity in rat cerebral cortical neurons by increasing brain-derived neurotrophic factor level and activating TrkB. Brain Res. 2008;1210:84-91.

32. Hagl S, Kocher A, Schiborr C, Kolesova N, Frank J, Eckert GP. Curcumin micelles improve mitochondrial function in neuronal PC12 cells and brains of NMRI mice - impact on bioavailability. Neurochem Int. 2015;89:234-42.

\section{Submit your next manuscript to BioMed Central and we will help you at every step:}

- We accept pre-submission inquiries

- Our selector tool helps you to find the most relevant journal

- We provide round the clock customer support

- Convenient online submission

- Thorough peer review

- Inclusion in PubMed and all major indexing services

- Maximum visibility for your research

Submit your manuscript at www.biomedcentral.com/submit

) Biomed Central 